\title{
pÿ I wish I had a crystal ball : Discourses and Potentials for Developing Academic Supervising
}

\section{Vehviläinen, Sanna}

2016-03-03

pÿVehviläinen , S \& Löfström , E 2016 , ' I wish I had a crystal ball : Discourses and Potentials for Developing Academic Supervising ' , Studies in Higher Education , vol. 41 , no. 3 , pp. 508-524 . https://doi.org/10.1080/03075079.2014.942272

http://hdl.handle.net/10138/231523

https://doi.org/10.1080/03075079.2014.942272

acceptedVersion

Downloaded from Helda, University of Helsinki institutional repository.

This is an electronic reprint of the original article.

This reprint may differ from the original in pagination and typographic detail.

Please cite the original version. 


\title{
ALMOST FINAL VERSION
}

\author{
To cite, please refer to:
}

Vehviläinen, S. \& Löfström, E. (2016). 'I wish I had a crystal ball’: Discourses and Potentials for Developing Academic Supervising. Studies in Higher Education, 41(3), 505524. http://dx.doi.org/10.1080/03075079.2014.942272

\section{I wish I had a crystal ball': Discourses and Potentials for Developing Academic Supervising}

\section{Sanna Vehviläinen \& Erika Löfström}

\begin{abstract}
Academic supervision of $\mathrm{PhD}$ dissertations and master's theses has traditionally been conceptualised as the pedagogy of the dyadic relationship between master and apprentice. Recently researchers have argued for a more systemic approach. Yet, many communities lack practices for sharing the pedagogical responsibility of supervision. Consequently individual teachers face the challenges of supervision alone. We have been involved in university pedagogical training where these challenges are explored. Data consist of 44 academics' learning tasks, from which we analysed to what extent and how supervision is interpreted as a social activity, and what kind of cultural elements appear in the teachers' discourses. We adopted the sociocultural approach to discourse analysis and treat the academics' experiences as reflections of their wider culture. A traditional supervisory discourse pervaded much of the challenges we identified in the academics' descriptions, however, there was also evidence of an aspiring process-orientated dialogical supervision discourse.
\end{abstract}


Keywords: academic supervision, higher education development, university pedagogy, university teachers, supervisors, $\mathrm{PhD}$ supervision 


\section{Introduction: From an individualist to a systemic culture in academic supervision}

Academic supervision - the supervising of academic theses and dissertations - has traditionally been conceptualised as the supervisor-supervisee relationship (e.g. Gurr 2001; Styles and Radloff 2001; Delamont, Atkinson and Parry 2004; Murphy, Bain and Conrad 2007; Deuchar 2008; Mainhard et al. 2009), and this view appears to have guided staff development initiatives as well. Research in this area has emphasised a master-apprentice pedagogy in which both parties are orientated towards producing the thesis and solving problems related to it. Thus, research approaches have often been interviews that focus on concepts of supervision and research (McGormack 2004; Murphy, Bain and Conrad 2007; Franke and Arvidsson 2011) or studies of ways in which the participants' concepts match (Gurr 2001; Deuchar 2008). At the same time becoming an academic and an expert in one's field has also been described as socialisation into the academic community (Becher 1994; Ylijoki 2000; Neumann, Parry and Becher 2002; Parry 2007). The pedagogical and the sociological approach have not interacted much in past supervision research.

Lately, however, research has also offered a more systemic-orientated view emphasising the role of the academic community in supervision. From this perspective, supervision of academic dissertations should be considered a systemic activity. This community-level practice systematically enhances the students' process of becoming academic experts, their engagement with their studies, the development of their academic identities and the strengthening of their participation in the academic community (Pearson and Brew 2002; Boud and Lee 2005; Dysthe, Samara and Westrheim 2006; Stubb 2012). Pedagogical scholarship, then, is not only a matter of knowledgeable, pedagogically-minded individual professors, but is also a well-functioning academic community that recognises its role as a 
pedagogical community as well as research community. An academic community is a multiagent system in which all levels interact and influence each other. Supervision cannot be conceptualised through any one aspect alone, but requires an analysis of how the various aspects interact (Pyhältö, Stubb and Lonka 2009).

Traditionally, supervision has been practised as a product-focussed activity taking place between master and apprentice, in which they both focus on the unfolding research artefact (the dissertation) and endeavour to solve any problems that arise. The dissertation provides the student the 'licence to do research'. The supervisor's expertise is based on research experience. By contrast in the systemic and learning-orientated approaches, the learning and work processes rather than the product is considered the primary focus of academic supervision (Gurr 2001; Pearson and Brew 2002; Austin 2009; Hopwood 2010). The object (target) of the supervisory activities and interventions should be the academic learning processes, as well as the generic work processes such as goal-setting, planning, evaluation, motivational processes and reorientation after encountering obstacles. These processes have, of course, always taken place in the learning of research, but in the traditional model they have remained implicit.

According to the more process-oriented view, supervision is a pedagogical activity that calls for pedagogical expertise in addition to research-related expertise. The academic supervisory process should be viewed as a learning process as well as a participatory process that shapes the identity of the supervisee. It is also relevant that the supervisor recognises the various resources and methods available in a supervisory context. Thus, supervision is a matter of pedagogical choices, rather than merely following the traditions of the disciplinary culture or local routines. 
A second lesson from the systemic view of academic supervision is to reconsider the agent of the supervision - from activity between individuals towards group-level as well as community-level activities (Pearson and Brew 2002; Dysthe, Samara and Westrheim 2006; Pyhältö, Stubb and Lonka 2009; Baker and Lattuca 2010; Hopwood 2010; Pyhältö et al. 2012; Stubb 2012; Jaldemark and Lindberg 2013). If we view learning as a sociocultural process whereby communities shape their activities and members continuously change their participation (Wenger 1998, Hopwood 2010), then we must view professors or other academic seniors as important but not the only relevant agents in the supervisory practice. Of course, supervision often tends to be carried out in dyadic teacher-student relationships, but also peer groups, research seminars, research teams and larger communities including research units, networks or doctoral schools should be viewed as agents of supervision (Baker and Lattuca 2010). Supervision, then, is best conceptualised simultaneously at individual, group and community levels. Despite the shift towards more process-focused and community-minded supervision apparent in research, academic communities often still lack the concepts and tools for sharing pedagogical responsibility for academic supervision. Consequently, in their daily work teachers face the contradictions of the current supervisory practice alone.

According to our experience as university pedagogical trainers, teachers attending university pedagogical courses in order to improve their competencies and scholarship, often find themselves analysing problems of teaching and supervision that, in fact, stem from malfunctioning community-level activity. We link this problem to what has been called the individualistic teaching culture, which is particularly characteristic of academic supervision, but relevant to higher education in general. Such a culture views pedagogical practice mainly as the work of an individual teacher rather than of a working community. Such a culture is 
characterised by a weak collective grasp of key pedagogical activities (planning, teaching, assessment), together with an individual teacher's experience of isolation from colleagues. Often this culture also hinders the sharing of problems. The phenomenon of 'blaming the student' (Biggs 1999) may occur: supervisory problems are attributed to 'poor students' or 'lack of student motivation or skill'. What is particular to university settings is an ambivalent teacher identity and the contradictions between research and teaching (cf. Hargreaves 2003). Such pressures are experienced in the work of individual supervisors.

\section{Challenging the individualist teaching culture in university pedagogical training}

Cultures are shaped by research, innovation and education policies, the balance in the research-teaching nexus, resources, leadership, as well as teachers' expertise and work identities. University pedagogical training is a potential arena in which these issues can be explored and local, practical grassroots-level solutions envisioned. Training individual teachers will not change the entire culture as such, but it enables teachers to create networks and collegial spaces across disciplinary borders, as well as to reflect on and reinterpret their own experiences and environments. Therefore, we believe that it is essential in university pedagogical training for teachers to be able to explore the indications of an individual teaching culture in their own environments and look for practical, accessible ways to challenge it. In order to do this, it is necessary to examine the current discourses, to what extent the individualistic traditional discourse prevails, and to what extent alternative discourse emerges.

We have been involved in such university pedagogical training, focusing particularly on supervision. In the courses, the above-mentioned challenges are recognised, analysed and interpreted as starting points for both individual and collective learning. Our paper provides 
an analysis of these developmental potentials by investigating the discourses in teachers' learning assignments in these courses. We identify the current contradictions in the supervisory system as they appear in the teachers' portrayals of problems and paradoxes in their supervisory practice, as well as their reports of what they consider rewarding and wellfunctioning aspects of their practice. We set out to answer the following research questions: 1) How is supervision interpreted as a social activity in the teachers' discourses?

2) What cultural elements appear in their discourse?

\section{Methodology: Discourses mirroring cultural assumptions}

University pedagogical training is a setting where cultural assumptions about academic teaching and supervision meet and collide. The analysis of university teachers' discourse provides a possibility to examine these assumptions, but also to view them as potential for development.

We analyse discourses as manifestations of the conceptions, practices and their justifications of the participants' communities (cf. Potter and Wetherell 1995; Wooffitt 2005). We have adopted the sociocultural approach to discourse analysis according to which discourses are evidence of social processes (Gee, Michaels and O'Connor 1992). Thus, as people engage in various activities, they exhibit elements of those wider social systems and their cultures. Supervision - very much one of the activities of academia - maintains conventions and traditions that reflect underpinning values and assumptions about learning. We take as our point of departure that when supervisors express their thoughts about supervision, it is within a social context and within the socially constructed parameters of that activity. We treat the respondents' experiences as reflections of the wider context and culture in which they are 
situated. The writings by the supervisors expose assumptions associated with their supervisory practices (e.g. Wooffitt 2005, 47-56). Descriptions of problems - unexpected or unwanted states of affair - as well as rewarding aspects, reveal the kinds of expectations and underlying assumptions supervisors have of themselves, and the norms to which they adhere. In sum, we examine the discourses from within which the supervisors come to our courses to develop their competencies. Verbalising their assumptions is a prerequisite for reconceptualising supervision.

Our analysis is theory-driven - by activity theory and sociocultural learning theory (Wenger 1998; Engeström 2000) - in that we view supervision as a social activity and that it is relevant to ask who are considered the agent of this activity, and what is considered its main object or target. However, we have also made room for a data-driven approach examining the particular themes through which problems and rewards are brought up by teachers. Our main focus is on the underlying normative expectations that these topics reveal about supervision.

We take into account that the texts produced in our courses are learning tasks, reflections produced by the teachers in a training context. In other words, they may contain both wishful thinking, as well as reflective attempts to understand the teacher's personal experiences and reality. We have not attempted to evaluate how truthful or accurate the teachers' texts are. Instead, we recognise the cultural content and basic assumptions of which they are constructed. We have read the materials as evidence of cultural norms, expectations and assumptions within academic communities. We have analysed the texts as discourse in which elements of teaching or supervisory cultures can be identified. Supervision is an institutional activity, entailing a set of (sometimes contradictory) cultural assumptions about research, 
expertise and learning. Since we are interested in developing academic cultures, we have reflected on the findings in terms of their developmental potentials.

\section{Data and method of analysis}

Our data consist of 44 pre-course learning tasks collected from five academic staff development courses for supervisors at a Finnish university. In the written pre-task, the participants were asked to describe 1) their main worry or concern in supervision, and 2) what they regarded as rewarding, well-functioning practices in supervision. The rationale for creating this pre-course learning task was that the courses should model and promote collegial and dialogic practice. Therefore, the object of a joint activity was approached and constituted through a mutual interpretative process. The task helped to create a sufficiently shared 'working definition of supervision' (cf. Wenger 1998) and expose assumptions, conceptualise the course participants' prior experiences, and reveal potential contradictions in their knowledge base. The discussions that have followed in the courses have facilitated the re-conceptualisation of the phenomenon of supervision.

The courses comprised 5 credits in the European Credit Transfer System (ECTS). Four of the courses were organised either on university campuses or in university faculties, in which case the participants could be expected to be relatively homogeneous in terms of disciplinary backgrounds. One course was a highly heterogeneous mixed-group course for academic staff from all campuses and faculties of the university. Participation in these courses is voluntary, but there are usually more applicants than can be accepted. The participants are university teachers and professors who wish to develop their supervision practices. They may be supervising theses at the bachelor's, master's or doctoral level. We contacted via e-mail those course participants who had previously participated in staff development courses on 
supervision (about 100 teachers altogether) and asked for their voluntary consent to allow us to use their pre-course learning tasks as research data. Fifty-six course participants consented. However, we were able to retrieve the tasks of 44 of the teachers, who formed our actual sample, and we numbered the data with numerical codes (1-44).

We answered the first research question by analyzing a) who are perceived to be the agents of supervision (a teacher acting alone/a collective agent) and b) what is implied as the object of the practice (product/process) (i.e. in line with ideas from activity theory; Engeström 2000, 2001). To the second research question we responded by analysing what assumptions, norms or attributions emerged in the data with respect to supervisory activity.

We created a matrix in which we listed the problems and the challenges described by the teachers and independently analysed who is the implied agent and what is the object of the practice. We then wrote observations about what were brought up as key themes in each text and what were the normative assumptions these themes revealed. We then cross-validated our interpretations by discussing the interpretation of each unit of analysis, until we reached an agreement. The process was highly iterative in nature with several rounds of readings and discussions of the interpretations, i.e. dialogic reliability check (cf. Åkerlind 2005). We continued to define the thematic observations into thematic discourses (cf. Braun and Clarke 2006), which we called Supervision as a Balancing Act, Diversity of Students, Fairness through equal allocation of time, Feedback and the Crystal Ball (i.e. the need to diagnose and predict the student's process). Some of the responses contained all the themes; some, only one or two. We then grouped all the listings in appropriate thematic categories, and once more cross-validated our interpretations through negotiation. 
We repeated the same protocol with the descriptions of rewarding practices. We found descriptions for the prerequisites of supervision in which the rewarding or well-functioning aspects of supervision were attributed to student characteristics, descriptions of teacher competence in the subject matter and descriptions of the humane, approachable and friendly teacher. In addition, we distinguished traces of pedagogical practices intended to support the thesis or dissertation process. Again, a response might contain all or just one or two of the themes.

We had an entirely uniform interpretation of agent and object in 20 cases. With regards to the agent of supervision, our interpretations coincided in 40 cases. Most of the differences in our analyses of the data pertained to the interpretation of the object of well-functioning practices. The reason for the differences was that, in many cases, the object was not apparent, in which cases we turned towards other discursive elements apparent in the material.. We discussed all interpretations until we reached consensus. Finally, we organised the material in terms of two polarities: an individual product-focused supervisory culture and a community-based processfocused culture. By using this polarity to discuss our results, we were able to identify the developmental and training potentials of these discourses

\section{The findings}

\section{Who supervises: The individual supervisor as the agent}

First, we analysed who was portrayed as the agent of supervision. The supervisors most often described their work through their own efforts, solutions, practices and habits. They viewed supervision primarily as an individual supervisor-student relationship, in which the supervisor was portrayed as the sole responsible decision-maker in supervisory matters. This was the case in 42 out of 44 responses. Eleven responses contained some mention of the 
community as an actor in supervision, but it existed merely in the form of an insufficient or a lacking community. Deficiencies were identified in the practices and pedagogical awareness in the community. In a sense the community was present, but as a weak agent lacking coordination and support structures for the individual supervisors. The idea of a research team or a peer support group as an agent in supervision did not specifically emerge in the data either. The research group or team was sometimes mentioned, only not as an agent, but rather as the object of the individual supervisor's leadership. We take this to reflect an individualist supervision culture.

In the extract below, a university teacher narrates her experiences in academic supervision. Her assignment is launched with the comment 'I don't know how to supervise!' Then she goes on to describe various contradictory practices in her teaching community, some of which are illustrated in the following excerpt:

I am an external evaluator for a master's thesis. There are weird things in the text. I check the original sources, which do not contain these oddities. The student has made them up. I report this to the professor in charge. The professor says that as this has passed the supervisor unnoticed, the supervisor has done a poor job. In my view, the student seems not-so-good since the references are wrong. I would like to lower the grade. In the professor's view the supervisor has acted badly and it is not the student's fault. I've been told to evaluate the product. Whom am I assessing? What am I assessing? (44)

What the teacher talks about cannot be attributed to a single actor. She describes various problems in the activities at the community level: lack of clear 'playing rules', lack of shared 
responsibility for supervisory activities, attempts to attribute the blame to various single actors (it's the fault of the student, it's the fault of the supervisor), a lack of clear learning goals and undefined notions of authorship and responsibility regarding the master's thesis as an autonomous student contribution.

\section{What is supervised? Expectations of influence on the student's process}

Little over half of the participants (frequency $\mathrm{f}=24$ ) described supervision as interventions that influence a student's work or attitudes, that this practice is somehow problematic and that the supervisor lacks the means to carry out such interventions successfully. This idea could be coined as follows: 'How do I make the student act/think/behave in a way that students are supposed to act/think/behave?' The sentences were often constructed using the words 'how do I make... '. The way in which the supervision and its objectives are described portrays the supervisor as being responsible for the student's study processes, including orientation towards the task, goal-setting, autonomy, timing and motivation.

How do I make the students work harder? (11)

How do I make the student understand easily that a thesis or dissertation requires taking an active role? (43)

How to make the student, even from the topic-selection stage, interested in a challenging rather than a safe but modest working process? (25)

Focus is not on the thesis alone, even if supervisors mention the deficiencies in the thesis or in the students' skills as challenges. In these extracts, the implication is that the supervisor should influence the central work processes related to conducting thesis or dissertation research; the problems are localised in the attitudes of the students, and the supervisor's role is to improve those attitudes. In those cases in which the focus was not on the student and the 
dissertation process, it tended to be on the product: the thesis or the dissertation. In some cases, the texts contained general thoughts about the nature of supervision and its overall opacity and it was not possible to determine the exact focus of these texts.

It is notable that supervisors' concern is focussed around the student's learning and work process: this implies that the agency is attributed to the student. However, instead of viewing this as a matter of pedagogy, shared activity and a topic for mutual discussion, it is implied that the burden of creating a change in attitude is on the supervisor.

\section{What is difficult about supervision?}

Supervision as a balancing act: Balancing student autonomy and supervisor direction In 28 responses, the difficulties or burdens of supervision were described as the balancing between two extremes or alternative actions. Typically, the balancing act took place between supervision intervention and allowing the students to find their way by themselves. The following quotation illustrates the balancing between directive supervision and the student's own decision making:

[The main worry/concern is] drawing the line and being encouraging. Where is the line between supervision and the student's own input necessary in a thesis? ... [H] ow can one draw the line in practice, other than saying that 'you just have to think about this yourself'? (40)

This category describes the supervisor's attempts to adjust the supervision to the students' needs. As the aim of supervision, the teachers defined supporting the students' learning process and independent agency. This was evident through the use of concepts such as supporting students'own thinking, independence, responsibility and freedom. The teachers 
were concerned with how much advice to give and how detailed it should be: What is 'too much' or 'too little' supervision? When should one intervene and when should one refrain from doing so? We interpreted the teachers' concerns about 'too much' supervision and their thoughts about how often and when to give and not to give advice to be indicative of a limited set of interventions that the teachers recognised and utilised. These concerns indicate that the teachers did not conceive of what they could do other than giving corrective feedback and advice.

It is noteworthy that the issue of balancing was viewed specifically as a problem or a challenge, not as a solution. Thus, a characteristic that by and large defines supervision, i.e. tailoring support according to the supervisee's needs and abilities, was seen as a problem. Supervision, then, was understood as a normative practice, i.e., as an activity that is somehow uniform, correct and would be successful if carried out according to a set of rules or guidelines.

Supervision as a balancing act: Balancing authorship and responsibility Concern for the proper amount of supervision indicates that supervisors also deal with the question of ownership and sharing responsibility. The teachers used concepts such as permission, appropriate, responsibility and ethical to describe the balancing act of ownership:

To what extent is it appropriate for the thesis to reflect the supervisor's conceptions and work? I think that the thesis should reflect the student's conceptions as much as possible, but what if this is not enough to get the thesis through? (7) 
The supervisors addressed the question of whose responsibility it is to make the key decisions in the thesis and under what conditions the work can be considered the student's. In the academic community, the issue of ownership is an ethical and a highly consequential question involving authorship issues and integrity. Academic authorship and ownership of one's work are matters that are constantly brought up by teachers in university pedagogical training. Yet what counts as authorship in academic dissertation should be negotiated on the community level.

\section{The diversity of students}

Student diversity was described as a problem or a challenge in fourteen responses. In some cases, the specific problem was that, owing to the diversity among students, the teacher had to act with each student in a different way. Diversity included differences in the students' knowledge or skills, differences in their independence and in their needs for support and activity in help seeking.

[The main worry/concern is] supervising students of different aptitude; some students are enthusiastic from the start and actively begin to work on their research question. Some seem to regress and require hands-on guidance. (3)

What makes diversity a problem? Should the students be more alike? Do the supervisors expect to be able to act the same way with all students? A more homogeneous body of students, with more homogeneous skills, expectations and needs, is a characteristic of the traditional supervisory culture. It seems to be difficult to conceive of supervision as systematic activity if interventions need to be locally fitted to the specific situation. The supervisors appeared to suggest that there should be general tools and practices that are 
applicable and will work well, regardless of the student and the situation. If the diversity of students is considered a problem, we miss out on the idea that supervision as pedagogical practice allows negotiated and tailored solutions, and thereby takes into account the students' different needs.

\section{Fairness through equal allocation of time}

Many supervisors $(f=16)$ connected the challenges of supervision with the limited amount of time available, and they sought solutions for effective use of their available time. Problems of time, scheduling and the constant atmosphere of rushing are often discussed as a feature of the academic working culture and experience (e.g. Ylijoki and Mäntylä 2003). The discourses of time experience are an interesting issue as such, but in our reading of the material we are interested in another dimension. A problem discussed by the supervisors was the equal treatment of students. Supervisors take equality to mean that they try to allocate the same amount of time for each student. The diversity of students, however, makes the equal allocation of time for all impossible. Giving the most time to the neediest students, which at first may seem like a reasonable principle, becomes problematic:

In my view, the biggest problem in supervision is that it is always a matter of one-on-one communication, and consequently the contexts and settings are always different. Some of my students have been very independent, needing only a small nudge to point them in the right direction. Students whom you need to guide hands-on most of the time are the opposite 'type'. Especially the latter type puts you in a tight position when you are struggling to manage your time. 
The diversity of the students thus makes hollow the fair promise of equal allocation of time among the supervisees. It is difficult to recognise what would count as "good enough", as supervisors' work does not seem to be manageable either in terms of time or in intervention strategies. It seems that while the supervisors treat themselves as responsible for attending to the learning, motivational and working processes of different students, they also contradict themselves in the expectation that the students' needs, abilities and working patterns should be uniform and homogeneous.

\section{Feedback}

Giving feedback and instructions were the principal means through which the supervisors considered supervision to have taken place. In nineteen responses, the teachers described giving feedback as a problem. More specifically, the challenges pertained to making the feedback reach its target:

With some student the supervision seems to flow naturally, but sometimes it feels like my message just doesn't reach the student. Or if it is an introverted student, I do not know how he or she understood my message. Are there tools available for handling these situations in supervision? (32)

Supervisors expect the students to know what to do with the feedback and act accordingly. If this does not happen, then the supervisors tended to look for the reasons in the students' attitudes. Corrective feedback provides yet another perspective:

How to provide critical feedback so that the students would perceive it as a positive challenge rather than a criticism, but also as a serious suggestion? (11) 
Feedback alone is simply not a sufficient tool in supervision, given the responsibility for the students' work processes that supervisors adopt. In particular, feedback, even when it is repeated and upgraded, does not work well in situations when there are problems in understanding the key issues of the research setting, theoretical concepts or methodology, or when the participants have grave differences in how to approach a situation or the research process. What is needed instead are interactional tools for eliciting student views, examining those views, engaging in reflection (Vehviläinen, 2009). Adding the diversity of these work processes (cf. the categories of Balancing Act and Student Diversity) makes it even more evident that feedback and advice alone are not sufficient tools.

\section{The Crystal Ball: The need to predict the end result of the process}

This category synthesises the elements of the individualist supervision discourse. Twentyseven of the responses indicated that the supervisors have a need to see, diagnose and predict the kinds of interventions with which they can successfully influence the students. The supervisors hope to influence the students' motivation, habits, pace, research orientation and level of achievement, because they perceive there to be in these. Thus, the supervisor attempts to identify the problem and eliminate it with a targeted intervention. Using the metaphor of one of the research participants, we call this phenomenon the 'crystal ball'. A crystal ball is needed to identify a students' attitude or orientation, to influence a student's behaviour and to find the 'right' intervention. Typically, supervisors identified a symptom and hoped to treat it with a suitable intervention. In addition, a 'crystal ball' was needed to identify whether a student was talented enough and worth the supervisor's time and effort. ${ }^{1}$ In

\footnotetext{
${ }^{1}$ In the Finnish system, while supervisors are free to choose their PhD students, they are often assigned responsibility for a certain amount of master's thesis supervisees. Thus, they are not completely free to choose whether they supervise or not, or not even who they supervise. The described approach may nevertheless affect their decisions in how they invest their time and effort in certain students.
} 
other words, paradoxically, the supervisors would need to be able to predict the outcome of the process in order to know whether it would be worth engaging in it in the first place.

I wish I had a crystal ball that told me how a new supervisee will fair, what support he or she needs and how much time it is worth putting into the process. If all of the variables were known at the beginning of the process, the formula for the optimal input-output ratio of a supervision relationship would be this: supervision with a certain input would allow for the maximum number of finished theses, and each of these would be as high a quality as possible considering the students 'prerequisites. (43)

It is only realistic to recognise that the supervision process will likely include challenges, and the problem with the 'crystal ball' approach is the idea that the challenges should somehow need to be eliminated from the process instead of acknowledging them and subjecting them to scrutiny and negotiation, making them an opportunity for learning. It is notable that the student is made the object of the supervisor's activity, instead of being an agent and a partner in a shared activity (Maxwell and Smyth 2011). The elements of successful supervisory process hosted in the student - motivation, competency, goals and activity - are left unexamined and unreflected upon, a 'black box'.

\section{What works well and what rewards are found in supervision?}

Attribution to student characteristics

Some teachers harboured the view that supervision works well when the student is an 'ideal student'. 
Based on my own experience, supervision has worked best with motivated students who are capable of working independently without detailed guidance from the supervisor. Sometimes I have had the experience that an unspoken rule in supervision is that the purpose of the thesis process is precisely to sort the wheat from the chaff. Then the teacher is not responsible for supporting the 'weaker'students, because it is self-evident that some will prove more talented than others and will receive better grades than others (31).

The quest for motivated, self-directed and able students appears to represent an implicit core pedagogy typical of the traditional master-apprentice pedagogy of supervision. Students' motivation and orientation to the thesis have, indeed, been shown to be among the key factors in predicting the success of $\mathrm{PhD}$ studies (i.e. engaging in studies and finalising the dissertation) (Stubb, Pyhältö and Lonka 2012; Lahenius and Martinsuo 2011). However, the relationship between the nature of a good supervision relationship and a good working relation will go unnoticed if success (or failure) is primarily viewed in terms of student characteristics. Attributing the entire success of supervision to student attributes contradicts both the ideal of fairness and the expectation to support different students' processes.

Teacher competence in the subject matter and the ability to provide related feedback Feedback was a central tool or practice mentioned as facilitating the supervision process positively. Some teachers mentioned their own subject matter competence and their own research activity as the cornerstones of what works in their supervision. This appears to be indicative of a master-apprentice view of pedagogy in which the supervisor knows when to correct the student and what kind of solutions will push the student in the right direction towards a successful end product. 
Individual supervision works well. I've received praise for taking responsibility and for being an encouraging supervisor. I can help with formulating the hypotheses, in defining the parameters and especially in the writing-up phase, in which analysing and discussing the findings are my strengths. (30)

The humane, approachable and friendly teacher

Many teachers seemed to hold the view that supervision skills also include elements other than subject matter competence, suggesting process-related competencies. Many teachers described their own readiness to engage with the supervision encounters. The readiness to engage included good communication skills, approachability, empathy, the ability to listen to students, and the ability to create a positive atmosphere. The teachers offered student feedback to support these claims. What the teachers ended up describing are prerequisites for interaction and good pedagogy.

Communication works well. I take my students into account. I am easily approachable. This is the kind of feedback I have received from my students. In my own view I can also provide feedback and be encouraging. (8)

Many teachers mentioned the ability to encourage and motivate students. This could be indicative of the fact that there are also supervisors who exhibit the opposite characteristics or competencies; unavailability, inability to engage with the students' concerns and lack of empathy for the student. The students who find themselves in these circumstances gravitate towards those supervisors who are known to be friendly. There is anecdotal evidence from the pedagogical staff development courses that the teachers perceived to be friendly also get to 
take responsibility for other teachers' supervision loads. Good supervision is, of course, not only about communication skills and empathy, but these qualities can be seen as prerequisites for a successful pedagogical encounter.

\section{Pedagogical practices focused on supporting the process}

The descriptions of rewards included various excerpts in which the teachers implied that they had identified a supervisory problem, carried out some pedagogical analysis of the issue and created a pedagogical intervention to address the problem. These practices included scheduling, systematic organisation of the supervisory meetings, careful negotiation of the goals of the supervisory process, and scaffolding, such as structuring the contents of a thesis or dissertation prior to getting started with writing:

I feel that one thing in which I have succeeded well is the structuring of the contents before starting to write the thesis. When the list of contents is comprehensive, it is easier to structure the materials from any reference materials. The contents get set up in a logical manner. Some of the subtitles can then be left out at the end. (29)

The above quotation illustrates how the teacher has recognised something in the research process that students struggle with and has come up with a way to structure the process. Sometimes the good practices may have been preceded by a problem to which the teacher had sought a solution. Sometimes the teachers made attempts to explain why something works, suggesting that there has been some level of pedagogical analysis with an attempt to explicate the teacher's rationales. The following is an example of a teacher who has 
introduced ideas of supervision, which align with current notions of more process- oriented, collective practice:

I have tried to provide opportunities for peer feedback and for students to take the role of peer supervisors. The students have discussed their work in groups and provided feedback. I believe that this has lowered the threshold for giving and receiving feedback. Peer supervision cannot entirely substitute the supervision by the teacher, but it gives the teacher the opportunity to observe the supervision process and intervene when the students need that. (31)

\section{A summary: Two discourses in teachers' texts}

The elements of both the traditional master-apprentice discourse and the emerging, processorientated dialogical discourse co-exist in the data, as they do in current higher education practices.

Both problematic and rewarding aspects of supervision in the teachers' texts produced evidence of the traditional supervisory discourse, as follows:

1) Supervision is mainly depicted as the activity and responsibility of a single supervisor.

2) The main supervisory interventions that are explicitly discussed are advice and feedback on text drafts.

3) It is considered a distraction that the students are different and have different competencies, aptitudes, working pace and needs.

4) The ethical principle of fairness is operationalised as the norm to spend equal amounts of time with each student, which causes frustration to the supervisor and does not work in practice. 
5) The discourse of connecting the success of supervision solely to students' attributes is apparent in the notion that supervision works well when the students are highly talented, self-reliant, 'ideal types', and especially in the concern of how to identify the best 'student material' and predict their success.

6) The discourse of 'academic excellence' attributes the expertise of supervision merely to the research skills and academic expertise of the supervisor and cites the high quality of a dissertation as the only potential indicator of a successful supervisory process.

The following elements, found both in the problem descriptions and in the rewards descriptions indicate that a process-oriented dialogical supervision is a potential emerging discourse among teachers, although not as prevalent and clear as the traditional supervisory discourse. Elements of this discourse are exposed especially in the pedagogical practices focused on supporting the process:

1) The expectation that most teachers have of themselves is of being responsible for influencing a student's work and learning process (issues such as motivation, selfesteem, work habits, planning, realistic goal-setting, etc.).

2) The idea of 'being on the student's side' is evident in a) distancing oneself from authoritarian supervision by being the 'humane teacher': 'I'm friendly, approachable, I can listen and maintain good interaction'; and b) an orientation to the imperative of being in the service of the student's learning process and expressing a general willingness to be so involved. 
3) Various descriptions in which teachers show that they have created a local pedagogical intervention to tackle a supervisory problem (i.e. .pedagogical practices focused on supporting the process)

4) The emerging group orientation (in the rewards or smoothly functioning supervisory practices): in some cases, the teacher takes up the responsibility of facilitating the group process in supervision, enabling the group as a whole to supervise their peers.

\section{Evaluation of the research process}

While a certain level of subjectivity is always involved in the interpretation of qualitative research data, we feel that by independently analysing the entire data set and then crossvalidating all of the interpretations, we have been able to arrive at justifiable conclusions about the data. With regards to the more theory-guided phase, i.e. identifying agency in supervision and the object of the joint activity, the components of activity theory helped us form a mutual understanding of how we as researchers might conceptualise supervision and provided us with a framework to guide the analysis. The fact that the data do not represent a single field or course, but were collected over a range of courses with teachers representing a variety of fields provides further support for the discourses identified: these are neither isolated nor field-specific, but permeate academic supervision on a more general level.

\section{Discussion: From the traditional towards the dialogical supervisory culture}

The identified themes describing the teachers' worries or concerns about supervision all appeared to verbalise the implicit assumption that supervisors, from their expert position should be able to influence the student's work process. Supervisors acknowledged having responsibility for supporting the development of students' independence and agency and 
mastering the research process. However, they try to do this diagnostically from a nondialogic expert position with corrective feedback as the main tool. The responsibility is vast, but opportunities to act are limited. There is, however, substantial learning potential in this discourse for developing supervision practices and alleviating the burden on supervisors.

The first potential lies in the conceptualisation of agency in supervision. The supervisors almost unanimously defined supervision as individual practice, attributed great responsibility to the supervisor, and found the work hard and burdensome. The fact that the participants mostly did not recognise a collegial aspect of supervision points towards a discrepancy between what prior research suggests about beneficial elements in supervision and the views and practices currently prevailing in the academia. The community, if mentioned at all, was nearly a non-existing community. Sharing responsibility in an individualist teaching culture easily boils down to assigning students to the teachers to be supervised. The teachers supervise as they see fit, and there is no shared responsibility. A more collaborative responsibility in supervision would mean a shared understanding of the various phases in the thesis process, its core learning challenges, its criteria and the key methods of supervision. A collaborative perspective may also help the teachers recognise how they could influence the mutual practices and redirect the culture towards a more collaborative one. According to recent research, the supporting of learning requires adopting a broader perspective. This means shifting the view from a supervisor-student relationship to supervision as a social practice that involves academic communities as learning environments (Dysthe, Samara and Westrheim 2006). This perspective requires a negotiation of meanings, shared curriculum development, development of supervision and its practices on a systemic level, and in general, community-wide discussion about supervision, including in departments, faculties and doctoral schools. One of the challenges of staff development is to empower teachers to 
engage in such activities and support them in strengthening the collegial networks needed for carrying out these activities in their university settings. The re-conceptualisation of agency in supervision can also help clarify the individual supervisor's role in relation to the processes and the products. A distinction between the supervision of processes and contents may make it possible to see which process tasks can be distributed.

Redefining agency in supervision also implies that when supervision takes place in a one-onone context there should still be a shared responsibility for the process. The student too is an agent responsible for the process and the product, not just someone who enjoys the benefit of supervision. In order to support agency, the students should be included as partners and allowed opportunities for practicing dialogical interaction. Dialogical interaction and mutual partnership are means through which supervision supports the students' agency and development as experts in their fields (Frischer and Larsson 2000; Dysthe, Samara and Westrheim 2006; Austin 2009; Jaldemark and Lindberg 2013). The nature of the responsibility, the interests and the competencies are naturally different between the supervisor and the student. When these are discussed openly, the distribution of the work, the rights and the responsibilities become more comprehensible.

Distinguishing among different agents in the process can help the supervisor solve the challenges of supervision. Sometimes supervisors interpret community-level issues as their personal problems. An example is students' systematic lack of certain skills at the start of the thesis process, the lack of mutual rules of play or the lack of assessment criteria. When teachers begin to distinguish between individual and community-level issues it will be easier to define the limits and limitations of one's work, and may help to alleviate the feeling of toiling alone. 
Second, the supervising role could be distributed among peer and seminar groups, as well as among research teams, who might adopt a more systematic, active and supportive role in the supervision. This will likely require raising the pedagogical awareness of these groups. In practice, this could take place by together developing a common set of evaluation criteria, adopting supervision agreements, benchmarking good practices or implementing research seminars in contexts where these have been lacking. The supervisors specifically view that they are toiling with the students' work processes. This orientation is in line with the latest views on supervision, according to which supervision entails influencing the student's working and learning processes and supporting his or her agency (e.g. Gurr 2001; Pearson and Brew 2002; Austin 2009; Hopwood 2010; Pyhältö et al. 2012; Stubb 2012). The supervisors, however, find it difficult to influence these processes and attribute the challenges in the work to problems in the students' attitudes. In a similar way, many of the wellfunctioning aspects of supervision are attributed to student characteristics (i.e. the view that everything works fine with talented and motivated students). In addition the supervisors perceive that they should influence the processes mostly through feedback and direct advice, based on diagnosed problems. However, if the student does not react in a desired way, the supervisor soon runs out of tools. Responding with reactive feedback is not sufficient, and it becomes necessary proactively to verbalise the work processes and related learning tasks. Supervisors also need to adapt different dialogical practices, means of inquiring and asking questions, means of verbalising and scaffolding learning tasks and conceptualising mutual goals and of evaluating the working process while underway (Dysthe, Samara and Westrheim 2006; Austin 2009). 
An emphasis on subject matter expertise and the need to influence the student's process in a rather implicit way may be the consequences of an authoritative tradition, in which the seniority of the supervisor and the corrective interventions are generalised into a model applied in all contexts, regardless of the circumstances. Negotiation with the students can be understood as reducing the supervisor's academic authority. Yet supervisors demand of themselves procedures to support the student's agency, while are trying to achieve this with reactive feedback.

Models that emphasise dialogical partnership appear to have the most to contribute to solving this dilemma. Instead of diagnosing the students' working process and giving feedback or corrective advice through individual supervision, the supervisors could point out aspects of the working process for mutual discussion. The supervisor then does not have to guess or predict what might work, but rather, the working processes become the object of shared discussion and negotiation. When the processes are mutually verbalised, the students learn to take responsibility for the interaction, the work processes and their own work habits. The key aspects of the working processes, i.e. goal setting, motivation, pace, dealing with challenges, reconciling research and personal life, then become objects of mutual inquiry and discussion. The supervisor will not need to have answers to every question that arises or be solely responsible for solving these problems and 'making the students act/think/behave' in a desired manner. Instead, the structuring and scheduling of different phases of the work and the working methods become the object of mutual negotiation involving individuals and community stakeholders (e.g. supervisors, students, faculties, research teams). The questions of how to treat students in an equal way, the equal allocation of time, and the overall expectation that all students must be treated the same, become dispensable. Supervision is likely the pedagogical practice that best allows for students' varying needs. Instead of getting 
rid of the negotiating, contextual nature of supervision, accepting these as characteristics of supervision increases the supervisor's set of tools and resources.

\section{Acknowledgements}

This work was supported by the Academy of Finland under Grant 252813 to the second author.

\section{References}

Austin, A. E. 2009. Cognitive apprenticeship theory and its implications for doctoral education: a case example from a doctoral program in higher and adult education. International Journal for Academic Development 14 (3): 179-183.

Åkerlind, G. 2005. Academic growth and development: How do university academics experience it? Higher Education 50: 1-32.

Baker, V.R., and L. R. Lattuca, 2010. Developmental networks and learning: toward an interdisciplinary perspective on identity development during doctoral study. Studies in Higher Education 35 (7):807-827.

Becher, T. 1994. The significance of disciplinary differences. Studies in Higher Education 19 (2): 151-161.

Biggs, J. 1999. Teaching for Quality Learning at University, Buckingham: SRHE and Open University Press,

Boud, D., and A. Lee. 2005. 'Peer learning' as pedagogic discourse of research education. Studies in Higher Education 30 (5): 501-516.

Braun, V., and V. Clarke. 2006. Using thematic analysis in psychology. Qualitative Research in Psychology 3: 77-101. 
Delamont, S., P. Atkinson, and O. Parry. 2004. Supervising the Doctorate. A guide to success. SRHE and Open University Press.

Deuchar, R. 2008. Facilitator, director, or critical friend?: Contradiction and congruence in doctoral supervisory styles. Teaching in Higher education 13 (4): 489-500.

Dysthe, O., A. Samara, and K. Westrheim. 2006. Multivoiced supervision of Master's students: a case study of alternative supervision practices in higher education. Studies in Higher Education 31 (3): 299-318.

Engeström, Y. 2000. From individual action to collective activity and back: developmental work research as an interventionist methodology. In Workplace studies. Recovering work practice and informing system design, ed. P. Luff, J. Hindmarsh and C. Heath, 150-166. Cambridge: Cambridge University Press. Engeström, Y. 2001. Expansive learning at work: Toward an activity theoretical reconceptualization. Journal of Education and Work 14 (1): 133-156.

Franke, A., and Arvidsson, B. 2011. Research supervisors' different ways of experiencing supervision of doctoral students. Studies in Higher Education 36 (1): 7-19.

Frischer, J., and K. Larsson. 2000. Laissez-faire in research education - an inquiry into a Swedish doctoral program. Higher Education Policy 13: 131-155.

Gee, J. P., S. Michaels, and M. C. O’Connor. 1992. Discourse analysis. In The Handbook of Qualitative Research in Education, ed. M. D. LeCompte, W. L. Millroy, and J. Preissle, 227291. San Diego, CA: Academic Press.

Gurr, G. M. 2001. Negotiating the 'Rackety Bridge' - a dynamic model for aligning supervisory style with research student development. Higher Education Research \& Development 20 (1): 81-92.

Hargreaves, A. 2003. Teaching in the Knowledge Society: Education in the Age of Insecurity. New York: Teachers' College Press and Buckingham: Open University Press. 
Hopwood, N. 2010. Doctoral experience and learning from a sociocultural perspective. Studies in Higher Education 35 (7): 829-843.

Jaldemark, J., and J. O. Lindberg. 2013. Technology-mediated supervision of undergraduate students' dissertations. Studies in Higher Education, 38: 1382-1392.

Lahenius, K., and M. Martinsuo. 2011. Different types of Doctoral Study Processes.

Scandinavian Journal of Educational Research 55 (6): 609-623.

Mainhard, T., R. van der Rijst, J. van Tartwijk, and T. Wubbels. 2009. A model for the supervisor-doctoral student relationship. Higher Education 58: 359-373.

Maxwell, T. W., and R. 2011. Higher degree research supervision: from practice toward theory. Higher Education Research \& Development 30 (2): 219-231.

McCormack, C. 2004. Tensions between student and institutional conceptions of postgraduate research. Studies in Higher Education 29 (3): 321-334.

Murphy, N., J. D. Bain, and L. Conrad. 2007. Orientations to research higher degree supervision. Higher Education 53: 209-234.

Neumann, R., S. Parry, and T. Becher. 2002. Teaching and learning in their disciplinary context: a conceptual analysis. Studies in Higher Education 27 (4): 405-417.

Parry, S. 2007. Disciplines and Doctorates. Dordrecht: Springer.

Pearson, M., and A. Brew. 2002. Research Training and Supervision Development. Studies in Higher Education 27 (2):135-150.

Potter, J., and M. Wetherell. 1995. Discourse Analysis. In Rethinking Methods in Psychology. ed. Smith, J.A., Harré, R., and van Langenhove, L. 80-92. London: Sage.

Pyhältö, K., J. Stubb, and K. Lonka. 2009. Developing a scholarly community as a learning environment for Ph.D. students. International Journal for Academic Development 14 (3): $221-232$. 
Pyhältö, K. , A. Toom, J. Stubb, and K. Lonka, 2012. Challenges of Becoming a Scholar: A Study of Doctoral Students' Problems and Well-Being. International Scholarly Research Notices, Article ID 934941, p.1-13. http://dx.doi.org/10.5402/2012/934941.

Stubb, J. 2012. Becoming a scholar. The dynamic interaction between the doctoral student and the scholarly community. PhD diss., University of Helsinki, Faculty of Behavioural Sciences.

Stubb, J., K. Pyhältö, and K. Lonka, 2012. The Experienced Meaning of Working with a PhD Thesis. Scandinavian Journal of Educational Research 56 (4): 1-18.

Styles, I., and A. Radloff. 2001. The synergistic thesis: student and supervisor perspectives. Journal of Further and Higher Education 25 (1): 97-106.

Vehviläinen, S. 2009. "Problems in the Research Problem: Criticism and Resistance in Academic Supervision Encounters." Scandinavian Journal of Educational Research 6 (2): $185-201$.

Wenger, E. 1998. Communities of Practice. Learning, Meaning, and Identity. Cambridge: Cambridge University Press.

Wooffitt, R. 2005. Conversation Analysis and Discourse Analysis. A Comparative and Critical Introduction. London: Sage.

Ylijoki, O-H. 2000. Disciplinary cultures and the moral order of studying. A case-study of four Finnish university departments. Higher Education 39: 339-362.

Ylijoki, O-H., and H. Mäntylä. 2003. Conflicting time perspectives in academic work. Time \& Society $12(1), 55-78$. 